\title{
Tolerability and Adverse Events of Adjuvant Chemotherapy for Rectal Cancer in Patients With Diverting Ileostomy
}

\author{
JUN TAKAHASHI, SHINGO TSUJINAKA, RYO MAEMOTO, YASUYUKI MIYAKURA, \\ KOICHI SUZUKI, RINTARO FUKUDA, RYOTARO SAKIO, ERIKA MACHIDA and TOSHIKI RIKIYAMA \\ Department of Surgery, Saitama Medical Center, Jichi Medical University, Saitama, Japan
}

\begin{abstract}
Background/Aim: The impact of diverting ileostomy on the feasibility of adjuvant chemotherapy (ACT) remains unclear. We retrospectively investigated the tolerability and adverse events of ACT for rectal cancer in patients with diverting ileostomy. Patients and Methods: Thirty-three patients who received ACT after curative resection with ileostomy construction for rectal cancer were analyzed. We assessed completion rate, the mean relative dose intensities, and the factors affecting the tolerability of ACT. Results: The completion rate of each chemotherapy regimen was 10 out of 16 patients in oral uracil-tegafur plus leucovorin (UFT/LV), 1 out of 3 patients in oral capecitabine (Capecitabine) and 2 out of 14 patients in capecitabine plus oxaliplatin (CAPOX). The mean relative dose intensities were $77 \%$ in UFT/LV, $48 \%$ in Capecitabine, and $57 \%$ of capecitabine and $42 \%$ of oxaliplatin in CAPOX. In multivariate analysis, laparoscopic surgery (Odds ratio=11 .6, $p=0.021$ ) and receiving preoperative chemoradiotherapy (Odds ratio $=32.4, p=0.021)$ were associated with treatment completion. Conclusion: Completion rate of ACT in patients with diverting ileostomy was lower than that of colorectal cancer patients in the previous studies. UFT/LV may be a more tolerable regimen than Capecitabine or CAPOX in colorectal cancer patients with diverting ileostomy.
\end{abstract}

Anastomotic leakage is one of the severe complications of the surgical treatment for rectal cancer, causing morbidity and mortality. Diverting ileostomy is constructed in lower rectal surgery with high risk of anastomotic leakage. Previous

This article is freely accessible online.

Correspondence to: Shingo Tsujinaka, MD, Department of Surgery, Saitama Medical Center, Jichi Medical University, 1-847, Amanumacho, Omiya-ku, Saitama 330-8503, Japan. Tel: +81 486472111, Fax: +81 486485188, e-mail: tsujinakas@omiya.jichi.ac.jp

Key Words: Adjuvant chemotherapy, adverse events, ileostomy, rectal cancer, tolerability. reports have demonstrated that constructing a diverting stoma reduces clinically relevant anastomotic leakage (1-3).

Several studies have proven that adjuvant chemotherapy (ACT) improves postoperative survival in patients with stage III colorectal cancer (4-6). In case of advanced lower rectal cancer, ACT is indicated in patients with ileostomy. However, there is scarce data regarding the tolerability of ACT for rectal cancer in patients with diverting ileostomy.

This retrospective cohort study aimed to investigate the tolerability and adverse events of ACT for rectal cancer in patients with diverting ileostomy.

\section{Patients and Methods}

Patients. Between April 2011 and March 2018, 33 patients with rectal cancer received ACT after curative resection with ileostomy construction in a single center, Saitama Medical center, Jichi Medical University. We retrospectively reviewed the medical charts of these patients.

ACT is indicated in patients with histologically confirmed stage III (any T, N1-3, M0; according to UICC TNM classification) (7) or high-risk stage II (T4, inadequately sampled lymph node, poorly differentiated tumor, lymphovascular invasion) rectal cancer (8). In the present study, patients who received preoperative chemoradiotherapy were also included.

Bioethics Committee for Clinical Research, Saitama Medical Center, Jichi Medical University approved this study (\#S19-164).

Regimens. Chemotherapy regimens were oral uracil-tegafur plus leucovorin (UFT/LV), oral capecitabine (Capecitabine) or capecitabine plus oxaliplatin (CAPOX). Treatment regimen was determined by the attending physicians. CAPOX regimen was initially recommended, and other regimens were alternatively chosen in consideration with comorbidities, performance status and preferences of the patients.

UFT/LV regimen comprised oral uracil-tegafur $300 \mathrm{mg} / \mathrm{m}^{2}$ daily plus leucovorin $75 \mathrm{mg}$ daily on days 1-28 of a 5-week cycle for a total of five cycles. Capecitabine regimen comprised oral capecitabine $2,500 \mathrm{mg} / \mathrm{m}^{2}$ daily on days $1-14$ of a 3-week cycle for a total of eight cycles. CAPOX regimen comprised oral capecitabine $2,000 \mathrm{mg} / \mathrm{m}^{2}$ daily on days $1-14$ plus intravenous oxaliplatin 130 $\mathrm{mg} / \mathrm{m}^{2}$ on day 1 of a 3 -week cycle for a total of eight cycles.

Dose adjustment was performed in case of drug toxicity. Adverse events were assessed according to the National Cancer Institute 
Common Terminology Criteria for Adverse Events (NCI CTCAE) version 4.0 (9).

Endpoints. The endpoints of this study were the treatment completion rate, the average relative dose intensities, the reasons for the discontinuation of ACT, and the rate of adverse events of each chemotherapy regimen. We also assessed the clinical factors affecting the discontinuation of ACT. The patient characteristics [age, sex, body mass index (BMI), and American Society of Anesthesiologists Physical Status Classification (ASA-PS)], the preoperative chemoradiotherapy, the surgical approach (open, laparoscopic), the postoperative high output stoma, the pathology stage, and the interval from surgery to ACT were retrieved from medical records. The postoperative high output stoma was defined as an output $\geq 2,000 \mathrm{ml}$ per day or an output $\geq 1500 \mathrm{ml}$ for two consecutive days $(10,11)$.

Statistical analysis. The statistical analyses were performed using EZR (Saitama Medical Center, Jichi Medical University, Saitama, Japan), which is a graphical user interface for the R software program (The R Foundation for Statistical Computing, Vienna, Austria) (12). Fisher's exact test was used for qualitative data and the Student- $t$ test or the Mann-Whitney $U$-test was used for quantitative data. A multivariate analysis was performed by logistic regression model. Statistical significance was established at $p<0.05$.

\section{Results}

Patient demographics and clinical characteristics. The characteristics of patients are listed in Table I. The median age of the patients was 64 years (range=34-79). There were 23 men and 10 women. Treatment regimens of ACT were UFT/LV in 16 patients, Capecitabine in 3 patients and CAPOX in 14 patients. Eight patients received preoperative chemoradiotherapy. The surgical approach included open surgery in 18 patients and laparoscopic surgery in 15 patients.

Tolerability and adverse events of ACT (all regimens). The overall completion rate of ACT was 13 out of 33. The percentages of actually received dose $(90-100 \%, 70-90 \%, 0$ $70 \%$ and $0 \%$ of the intended dose) in each cycle of each regimens are shown in Figures 1-3. The mean relative dose intensity was the highest in UFT/LV regimen $(76.6 \%)$ and the lowest in oxaliplatin in CAPOX regimen $(42.0 \%)$. Grade 3 adverse events occurred in 11 out of 33 patients. The reasons for discontinuation of ACT included adverse events in 16, patient's refusal in 3 , and cancer recurrence in 1 . The details of tolerability and adverse events of each regimen are described as follows.

Tolerability of UFT/LV. Ten out of 16 patients completed the $\mathrm{UFT} / \mathrm{LV}$. The mean of relative dose intensity was $76.6 \%$ (Table II). Six patients discontinued the treatment without dose reduction (Figure 1). The reasons for non-completion were related to adverse events in 5 patients and patient refusal in one. A total of 10 patients experienced adverse
Table I. Clinical and demographic characteristics of patients $(n=33)$.

\begin{tabular}{lc}
\hline Characteristics & \\
\hline Age, years* & $64(34-79)$ \\
Gender & 23 \\
$\quad$ Male & 10 \\
$\quad$ Female & \\
Regimens of ACT & 16 \\
$\quad$ UFT/LV & 3 \\
Capecitabine & 14 \\
CAPOX & \\
Surgical approach & 15 \\
$\quad$ Laparoscopic & 18 \\
Open & \\
Preoperative chemoradiotherapy & 8 \\
$\quad$ Yes & 25 \\
$\quad$ No & \\
Pathological stage & 8 \\
$\quad$ II & 25 \\
III & $49(27-88)$ \\
Interval from surgery to ACT, days* & \\
\hline
\end{tabular}

*Data presented as mean (range). UFT/LV, Uracil-tegafur plus leucovorin; CAPOX, capecitabine plus oxaliplatin; ACT, adjuvant chemotherapy.

events of any grade, and 3 patients experienced grade 3 adverse events. The adverse events causing treatment discontinuation were anorexia (4/16) and creatinine increase (1/16) (Table III). Grade 3 adverse events are diarrhea (2/16), dehydration (1/16), creatinine increase (1/16), small intestinal obstruction (1/16) (Table IV).

Tolerability of Capecitabine. One out of 3 patients completed the Capecitabine. The mean of relative dose intensity was $47.6 \%$ (Table II). Two patients required dose reduction and 1 could complete the planned treatment (Figure 2). Two patients did not complete the treatment, due to adverse events and patient refusal. A total of 2 patients experienced adverse events of any grade, and 1 patient experienced grade 3 adverse events. The adverse events causing treatment discontinuation were neutropenia (1/3) (Table III). Grade 3 adverse event was hand foot syndrome (1/3) (Table IV).

Tolerability of CAPOX. Two out of 14 patients completed the Capecitabine. The mean relative dose intensity of capecitabine and oxaliplatin were $57.1 \%$ and $42.0 \%$, respectively (Table II). Because of the adverse events, 4 patients changed from CAPOX regimen to oral capecitabine alone. The treatment changes were performed from the second cycle in 2 patients, from the fourth cycle in 1 patient, and from the seventh cycle in 1 patient. After changing treatment, 2 patients received a total of seven cycles and 2 patients could complete eight cycles. The reasons for noncompletion were related to adverse events in 10 patients, 


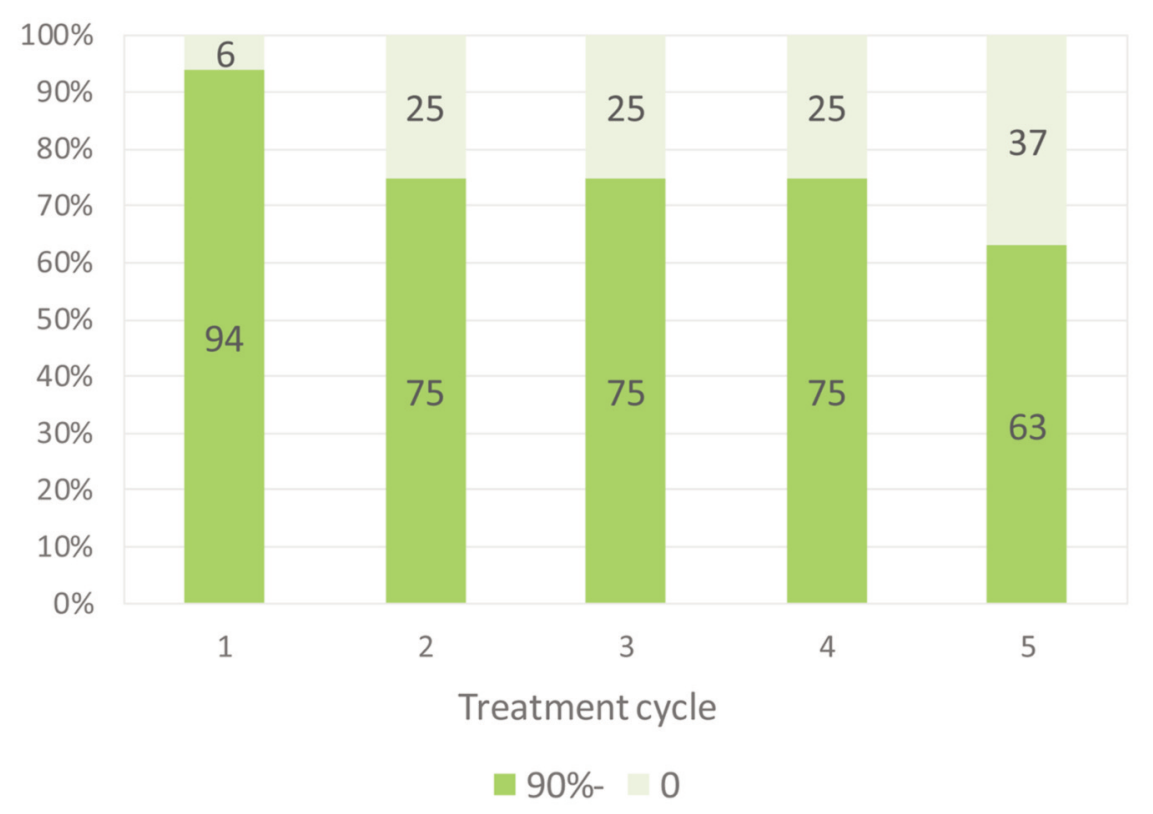

Figure 1. Percentage of received dose of UFT in each cycle of uracil-tegafur plus leucovorin (UFT/LV) regimen.

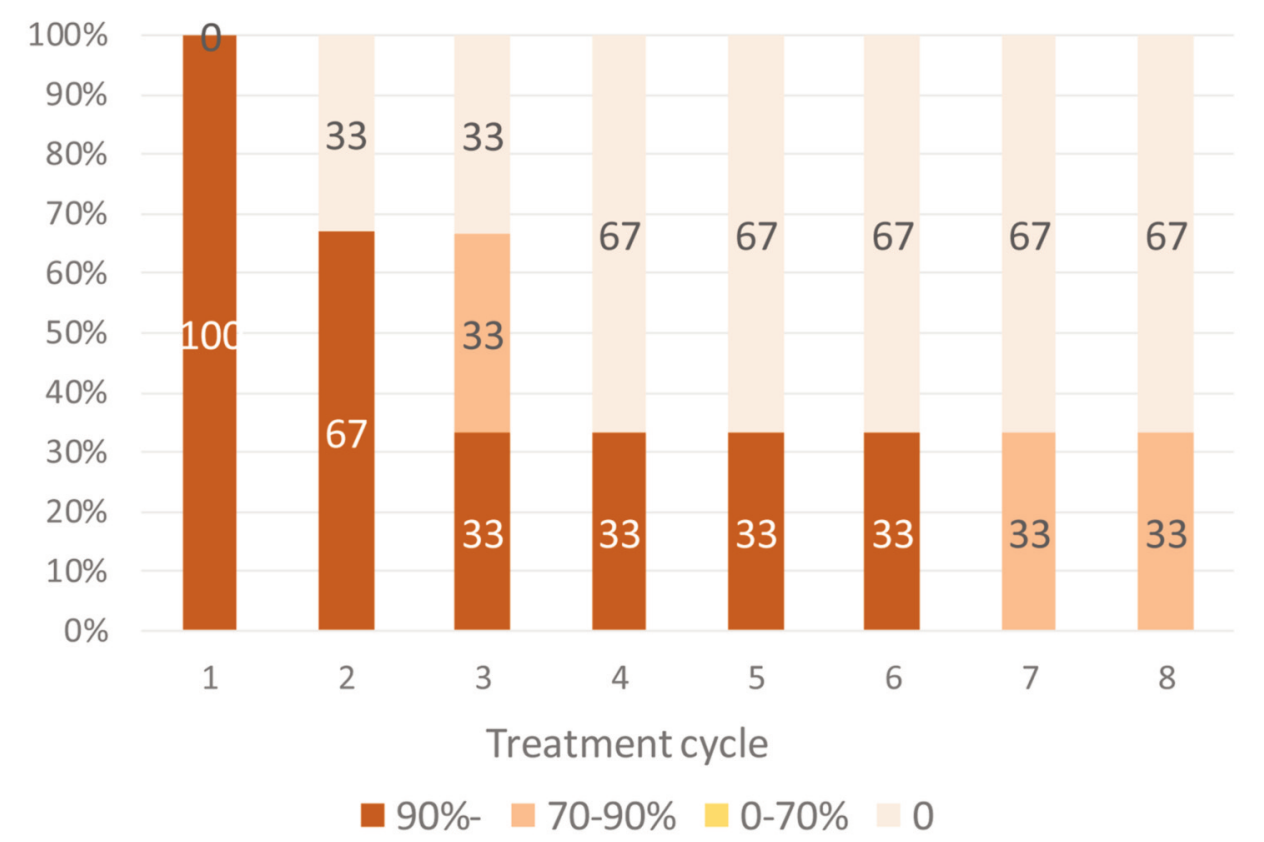

Figure 2. Percentages of received dose of Capecitabine in each cycle of Capecitabine regimen.

patient refusal in 1 , and recurrence of rectal cancer in 1 patient. All patients $(n=14)$ experienced adverse events of any grade, and 3 patients experienced grade 3 adverse events. The adverse events causing treatment discontinuation were stomatitis (3/14), diarrhea (2/14), anorexia (1/14), vomiting (1/14), peripheral neuropathy $(1 / 14)$, neutropenia
(1/14), and allergy (1/14) (Table III). Grade 3 adverse events were anorexia (1/14), vomiting (1/14), diarrhea (1/14), dehydration (1/14), and thrombocytopenia (1/14) (Table IV).

Clinical factors affecting the tolerability of ACT. The clinical characteristics of the treatment completion and non- 

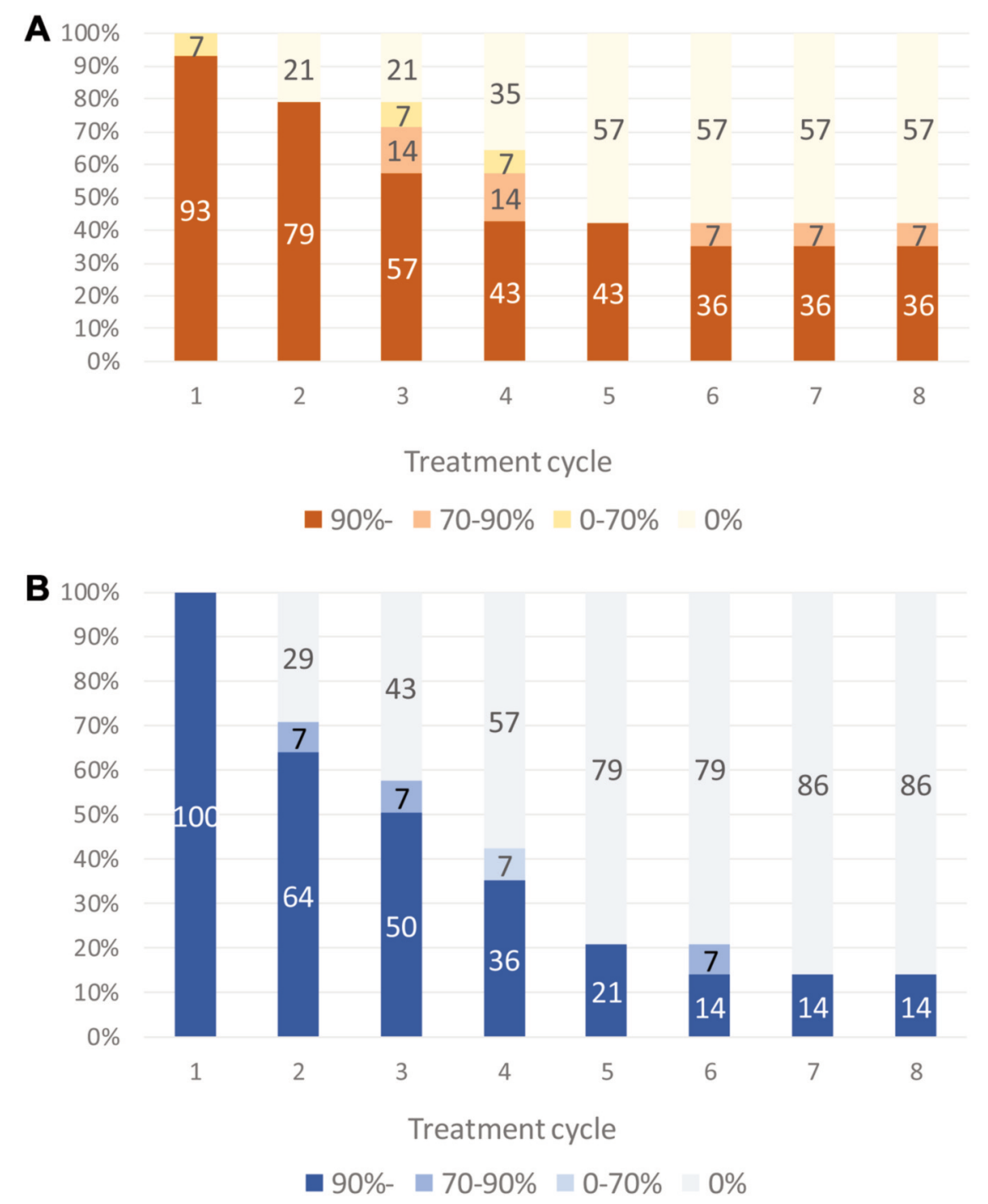

Figure 3. (A) Percentages of received dose of Capecitabine in each cycle of capecitabine plus oxaliplatin (CAPOX) regimen. (B) Percentages of received dose of Oxaliplatin in each cycle of capecitabine plus oxaliplatin (CAPOX) regimen.

completion groups are shown in Table V. One patient who discontinued ACT because of recurrence was excluded and a total of 32 patients were analyzed. There were 15 patients in the completion group (including the 2 patients who completed the treatment after changing from CAPOX to Capecitabine) and 17 patients in the non-completion group. Univariate analysis revealed that laparoscopic surgery $(p=0.031)$ and preoperative chemoradiotherapy ( $p=0.033$ ) were significantly more frequent in the completion group than in the noncompletion group. The incidence of postoperative high output stoma was higher in the non-completion group $(p=0.041)$. There were no significant differences in age, gender, regimen, BMI, ASA-PS, pathology stage and interval from operation to start of ACT. Laparoscopic surgery [odds ratio $(\mathrm{OR})=11.6$;
$95 \%$ confidence interval $(\mathrm{CI})=1.44-92.8 ; p=0.021$ and preoperative chemoradiotherapy $(\mathrm{OR}=32.4 ; 95 \% \mathrm{CI}=1.70$ $619 ; p=0.021)$ ] were independently associated with the completion of ACT in the multivariate analysis. There was no statistically significant relationship between the incidence of the high output stoma and the preoperative chemoradiotherapy or the surgical approach.

\section{Discussion}

In this study, we evaluated the tolerability of ACT for rectal cancer in patients with diverting ileostomy. The completion rate of ACT was relatively lower than that reported in the literature for colorectal cancer. In our study, the completion 
Takahashi et al: Adjuvant Chemotherapy in Ileostomy Patients

Table II. Completion rate and relative dose intensity (RDI) of each regimen.

\begin{tabular}{lc}
\hline Regimens & $\begin{array}{c}\text { Completion } \\
\text { rate }\end{array}$ \\
\hline UFT/LV & $10 / 16$ \\
Capecitabine & $1 / 3$ \\
CAPOX & $2 / 14$ \\
Total & $13 / 33$ \\
\hline & RDI \\
\hline UFT/LV & $76.6 \%$ \\
Capecitabine & $47.6 \%$ \\
CAPOX & \\
Capecitabine & $57.1 \%$ \\
Oxaliplatin & $42.0 \%$ \\
\hline
\end{tabular}

UFT/LV, Uracil-tegafur plus leucovorin; CAPOX, capecitabine plus Oxaliplatin.

rates of UFT/LV, Capecitabine and CAPOX were 10 out of 16 patients, 1 out of 3 patients and 2 out of 14 patients respectively, although previous studies in Japanese patients with colorectal cancer have reported $73-77 \%, 66 \%$ and $73.7 \%$, respectively $(5,13-15)$. In addition, previous studies have shown that low completion rate and low relative dose intensity of ACT had negative impact on overall survival rate $(16,17)$.

To discuss about the association between lower completion rate of ACT and ileostomy, it is necessary to consider the increased incidence of adverse events in CAPOX regimen (Tables III and IV) and the decreased sustainability in Capecitabine or CAPOX regimens (Figures 2 and 3) when indicating ACT to patients with diverting ileostomy. The completion rate of CAPOX was only 2 out of 14 patients, and 2 patients completed the treatment after switching to Capecitabine alone. A previous study with a larger number of Japanese patients regarding safety and efficacy of CAPOX as adjuvant chemotherapy (MCSCO1024) reported a completion rate of $73.7 \%$, which included switching to capecitabine alone (13). In that study, reasons for discontinuation of ACT were patient refusal of $16.8 \%$, disease recurrence of $5.8 \%$, and adverse event of $3.7 \%$. On the other hand, most of the reasons for the discontinuation in present study were the adverse events. Similar to the previous study by Danno et al. (13), the most frequent adverse event in our study was peripheral neuropathy. However, the adverse events causing the discontinuation of ACT were gastroenterological events such as stomatitis, diarrhea, anorexia, and vomiting. In our study, discontinuation of ACT was mostly observed within the fourth cycle. These results suggest that adequate monitoring of the gastroenterological symptoms and changing the dose early may contribute to a higher treatment completion rate.
Table III. Reasons for discontinuation of each regimen.

\begin{tabular}{|c|c|c|c|c|}
\hline & $\begin{array}{c}\text { UFT/LV } \\
(n=16)\end{array}$ & $\begin{array}{c}\text { Capecitabine } \\
(\mathrm{n}=3)\end{array}$ & $\begin{array}{c}\text { CAPOX } \\
(n=14)\end{array}$ & $\begin{array}{c}\text { All } \\
(\mathrm{n}=33)\end{array}$ \\
\hline \multicolumn{5}{|l|}{ Adverse events } \\
\hline Stomatitis & & & 3 & 3 \\
\hline Diarrhea & & & 2 & 2 \\
\hline Anorexia & 4 & & 1 & 5 \\
\hline Vomiting & & & 1 & 1 \\
\hline Peripheral neuropathy & & & 1 & 1 \\
\hline Neutropenia & & 1 & 1 & 2 \\
\hline Allergy & & & 1 & 1 \\
\hline Creatinine increased & 1 & & & 1 \\
\hline \multicolumn{5}{|l|}{ Others N $(\%)$} \\
\hline Patient's refusal & 1 & 1 & 1 & 3 \\
\hline Recurrence & & & 1 & 1 \\
\hline
\end{tabular}

UFT/LV, Uracil-tegafur plus leucovorin; CAPOX, capecitabine plus Oxaliplatin.

In the present study, the UFT/LV regimen showed a trend for higher tolerability than Capecitabine or CAPOX. Although the difference in completion rate of each ACT regimen did not reach statistical significance in present study, this result must be carefully interpreted considering the small number of studied patients and the decision bias in the selection of ACT. The completion rate for UFT/LV $(10 / 16)$ was lower than in the ACTS-CC trial $(73.4 \%)$, but the mean relative dose intensity of UFT/LV in our study $(76.6 \%)$ was similar to the one reported in the ACTS-CC trial $(76.5 \%)(15)$. The overall incidences of any grade and grade 3 adverse events were $63.5 \%$ and $18.8 \%$ respectively, in this study, while the ACTS-CC trial reported $73.7 \%$ and $14.4 \%$ (15). These results suggest that the feasibility of ACT with UFT/LV in patients with ileostomy is acceptable.

The analysis of clinical factors affecting the tolerability of ACT showed that patients with laparoscopic surgery and preoperative chemoradiotherapy were significantly more frequent in the completion than in the non-completion group. Increased tolerability of ACT after laparoscopic surgery might be associated with better postoperative recovery after minimal invasive surgery. Previous studies have demonstrated that laparoscopic colectomy improved shortterm surgical outcome $(18,19)$. Kim et al. have shown that laparoscopic colectomy contributed to greater compliance and earlier initiation of ACT (20).

There is scarce data regarding the relationship between preoperative chemoradiotherapy and tolerability of ACT. In present study, the patients receiving preoperative chemoradiotherapy had already been exposed to chemotherapy before ACT. Therefore, this experience may contribute to improved management for adverse events and dose reduction compared to those without preoperative chemoradiotherapy. Postoperative 
Table IV. Adverse events for each regimen.

\begin{tabular}{|c|c|c|c|c|c|c|}
\hline \multirow{2}{*}{$\begin{array}{l}\text { Regimen } \\
\text { Adverse events }\end{array}$} & \multicolumn{2}{|c|}{ UFT/LV $(n=16)$} & \multicolumn{2}{|c|}{ Capecitabine $(n=3)$} & \multicolumn{2}{|c|}{ CAPOX $(n=14)$} \\
\hline & All grades & Grade 3 & All grades & Grade 3 & All grades & Grade 3 \\
\hline Anorexia & 4 & & & & 2 & 1 \\
\hline Stomatitis & & & & & 4 & \\
\hline Vomiting & 1 & & & & 2 & 1 \\
\hline Diarrhea & 2 & 2 & & & 2 & 1 \\
\hline dehydration & 2 & 1 & & & 1 & 1 \\
\hline Fever & 1 & & & & & \\
\hline Small intestinal obstruction & & 1 & & & & \\
\hline Peripheral neuropathy & & & & & 6 & \\
\hline Hand foot syndrome & & & 1 & 1 & 1 & \\
\hline Anemia & 1 & & & & 2 & \\
\hline Thrombocytopenia & & & & & 2 & 1 \\
\hline Neutropenia & & & 1 & & 3 & \\
\hline Creatinine increased & 2 & 1 & & & 1 & \\
\hline Blood bilirubin increased & & & & & 1 & \\
\hline AST increased & 2 & & & & & \\
\hline
\end{tabular}

Some cases overlapped. UFT/LV, Uracil-tegafur plus leucovorin; CAPOX: capecitabine plus Oxaliplatin; AST, asparate aminotransferase.

Table V. Analysis of clinical factors completion group versus non-completion group.

\begin{tabular}{|c|c|c|c|c|c|}
\hline & \multirow{2}{*}{$\begin{array}{l}\text { Completion } \\
(\mathrm{n}=15)\end{array}$} & \multirow{2}{*}{$\begin{array}{l}\text { Non-completion } \\
\quad(\mathrm{n}=17)\end{array}$} & \multirow{2}{*}{$\begin{array}{l}\text { Univariate } \\
p \text {-Value }\end{array}$} & \multicolumn{2}{|c|}{ Multivariate } \\
\hline & & & & Odds ratio $(95 \% \mathrm{CI})$ & $p$-Value \\
\hline Age $^{1}$, years & $61(40-73)$ & $66(34-79)$ & 0.17 & & \\
\hline Gender & & & 0.71 & & \\
\hline Male & 11 & 11 & & & \\
\hline Female & 4 & 6 & & & \\
\hline Regimens of ACT & & & 0.26 & & \\
\hline UFT/LV & 10 & 6 & & & \\
\hline Capecitabine & 1 & 2 & & & \\
\hline CAPOX & 4 & 9 & & & \\
\hline $\mathrm{BMI}^{1}$ & $20.6(16.4-28.3)$ & $22.3(18.3-25.4)$ & 0.15 & & \\
\hline ASA-PS & & & 0.29 & & \\
\hline 1 & 6 & 4 & & & \\
\hline 2 & 8 & 8 & & & \\
\hline 3 & 1 & 5 & & & \\
\hline Surgical approach & & & 0.031 & & 0.021 \\
\hline Laparoscopic ${ }^{3}$ & 10 & 4 & & $11.6(1.44-92.8)$ & \\
\hline Open ${ }^{2}$ & 5 & 13 & & 1.00 & \\
\hline Preoperative CRT & & & 0.033 & & 0.021 \\
\hline Yes $^{3}$ & 6 & 1 & & $32.4(1.70-619)$ & \\
\hline $\mathrm{No}^{2}$ & 9 & 16 & & 1.00 & \\
\hline Pathological stage & & & 1 & & \\
\hline II & 4 & 4 & & & \\
\hline III & 11 & 13 & & & \\
\hline $\begin{array}{l}\text { Interval from surgery to ACT, days } \\
\text { mean (range) }\end{array}$ & $47(27-79)$ & $49(33-88)$ & 0.77 & & \\
\hline High output stoma & & & 0.041 & & 0.061 \\
\hline Yes $^{3}$ & 4 & 11 & & $0.14(0.018-1.10)$ & \\
\hline $\mathrm{No}^{2}$ & 11 & 6 & & 1.00 & \\
\hline
\end{tabular}

${ }^{1}$ Data presented as median (range); ${ }^{2}$ Control in multivariate analysis; ${ }^{3}$ Object in multivariate analysis. CI, Confidence interval; ACT, adjuvant chemotherapy; UFT/LV, uracil-tegafur plus leucovorin; CAPOX: capecitabine plus Oxaliplatin; BMI, body mass index; ASA-PS, American Society of Anesthesiologists Physical Status Classification; CRT, chemoradiotherapy. 
high output stoma was associated with non-completion, although stoma output and dehydration were well controlled by medication before ACT started. Three patients who suffered from chemotherapy-induced diarrhea also experienced postoperative high output stoma before ACT. The incidence of postoperative high output stoma may be indicator of high risk for adverse events.

Ileostomy occasionally causes dehydration and acute kidney disease due to the high output stoma and some patients need readmission because of stoma associated complications $(21,22)$. Robertson et al. (23) reported that the ileostomy was associated with severe chemotherapyinduced diarrhea and that it required chemotherapy regimen changes. In our study, 4 out of 33 patients experienced chemotherapy-induced diarrhea, and in 3 of the 4 it was of grade 3 . One patient experienced grade 3 acute kidney disease and needed rehospitalization. The incidence of the chemotherapy-induced diarrhea was not higher than in previous studies, whereas the percentage of grade 3 was higher $(13,15,23)$. These results indicated that once diarrhea is induced by ACT, presence of ileostomy might be a prognostic factor for severe adverse events.

Certain reports have addressed the timing of stoma closure in the context of ACT, but the appropriate timing of ileostomy closure is still controversial. Hajibandeh et al. (24), in a meta-analysis regarding ileostomy closure during versus after ACT, showed that there was no significant difference in surgical complication and length of postoperative hospital stay after stoma closure. Zhen et al. (25) demonstrated that patients who underwent stoma closure 6 months after surgery received more cycles of ACT than patients who underwent stoma closure 3 months after surgery. Brown et al. (26) reported that overall survival was similar in patients who underwent ileostomy closure before and after ACT for rectal cancer. There is no report about the relationship between the completion rate of ACT and the diverting ileostomy. Currently, a randomized clinical trial (27) studying the completion of ACT early versus late stoma closure (CoCStom trial) is ongoing.

Our study has potential limitations. It is a retrospective study, with a small sample size. Another limitation is that dose reduction criteria and discontinuation criteria were not strictly defined and were determined by the attending physicians. In this study, we focused specifically on tolerability and adverse event of ACT in patients with ileostomy. We will continue to follow up our patients, and investigate relationship between lower completion rate of $\mathrm{ACT}$, interval from resection of cancer to stoma closure and long-term survival in our future research.

In conclusion, the completion rate of ACT in patients with diverting ileostomy was lower than that of colorectal cancer patients in the previous studies. UFT/LV was reasonably tolerated, while Capecitabine or CAPOX were difficult to continue due to adverse events. Dose reduction or modification of regimens may be considered for sustainable ACT. Larger randomized control studies are warranted to evaluate the tolerability of ACT regimens in patients with diverting ileostomy, to identify the optimal regimen.

\section{Conflicts of Interest}

The Authors declare no conflicts of interest for this article.

\section{Authors' Contributions}

JT and ST proposed study conception and design. RM, RF, RS and EM performed data collection and acquisition. JT and ST interpreted the data. JT drafted the manuscript. ST, RM, RF, RS and EM edited the manuscript. YM, KS and TR had a role in critical revision of the manuscript. All Authors have read and approved the final version of the manuscript.

\section{Acknowledgements}

The Authors would like to thank Editage (www.editage.com) for English language editing.

\section{References}

1 Matthiessen P, Hallbook O, Rutegard J, Simert G and Sjodahl $\mathrm{R}$ : Defunctioning stoma reduces symptomatic anastomotic leakage after low anterior resection of the rectum for cancer: A randomized multicenter trial. Ann Surg 246(2): 207-214, 2007. PMID: 1766798. DOI: 10.1097/SLA.0b013e3180603024

2 Qu H, Liu Y and Bi DS: Clinical risk factors for anastomotic leakage after laparoscopic anterior resection for rectal cancer: A systematic review and meta-analysis. Surg Endosc 29(12): 36083617, 2015. PMID: 25743996. DOI: 10.1007/s00464-015-4117$\mathrm{x}$

3 Tan WS, Tang CL, Shi L and Eu KW: Meta-analysis of defunctioning stomas in low anterior resection for rectal cancer. Br J Surg 96(5): 462-472, 2009. PMID: 19358171. DOI: 10.1002/bjs.6594

4 Andre T, Boni C, Navarro M, Tabernero J, Hickish T, Topham C, Bonetti A, Clingan P, Bridgewater J, Rivera F and de Gramont A: Improved overall survival with oxaliplatin, fluorouracil, and leucovorin as adjuvant treatment in stage II or III colon cancer in the mosaic trial. J Clin Oncol 27(19): 31093116, 2009. PMID: 19451431. DOI: 10.1200/jco.2008.20.6771

5 Shimada Y, Hamaguchi T, Mizusawa J, Saito N, Kanemitsu Y, Takiguchi N, Ohue M, Kato T, Takii Y, Sato T, Tomita N, Yamaguchi S, Akaike M, Mishima H, Kubo Y, Nakamura K, Fukuda $\mathrm{H}$ and Moriya Y: Randomised phase III trial of adjuvant chemotherapy with oral uracil and tegafur plus leucovorin versus intravenous fluorouracil and levofolinate in patients with stage III colorectal cancer who have undergone japanese D2/D3 lymph node dissection: Final results of JCOG0205. Eur J Cancer 50(13): 2231-2240, 2014. PMID: 24958736. DOI: 10.1016/ j.ejca.2014.05.025

6 Twelves C, Wong A, Nowacki MP, Abt M, Burris H, 3rd, Carrato A, Cassidy J, Cervantes A, Fagerberg J, Georgoulias V, 
Husseini F, Jodrell D, Koralewski P, Kroning H, Maroun J, Marschner N, McKendrick J, Pawlicki M, Rosso R, Schuller J, Seitz JF, Stabuc B, Tujakowski J, Van Hazel G, Zaluski J and Scheithauer W: Capecitabine as adjuvant treatment for stage III colon cancer. N Engl J Med 352(26): 2696-2704, 2005. PMID: 15987918. DOI: 10.1056/NEJMoa043116

7 Brierley JD, Gospodarowicz MK, Wittekind C (eds): TNM Classification of Malignant Tumours, $8^{\text {th }}$ Edition. WileyBlackwell, pp 73-77, 2016.

8 Simillis C, Singh H, Afxentiou T, Mills S, Warren OJ, Smith JJ, Riddle P, Adamina M, Cunningham D and Tekkis PP: Postoperative chemotherapy improves survival in patients with resected high-risk stage II colorectal cancer: Results of a systematic review and meta-analysis. Colorectal Dis, 2020. PMID: 31999888. DOI: 10.1111/codi.14994

9 National Cancer Institute Common Terminology Criteria for Adverse Events (CTCAE)v4.0 Available at: http://ctep.cancer. gov/protocolDevelopment/electronic_applications/ctc.htm\#ctc_4 0 (Last accessed on July 24th, 2020)

10 Arenas Villafranca JJ, Lopez-Rodriguez C, Abiles J, Rivera R, Gandara Adan N and Utrilla Navarro P: Protocol for the detection and nutritional management of high-output stomas. Nutr J 14: 45, 2015. PMID: 25956387. DOI: 10.1186/s12937-015-0034-Z

11 Baker ML, Williams RN and Nightingale JM: Causes and management of a high-output stoma. Colorectal Dis 13(2): 191-197, 2011. PMID: 19888956. DOI: 10.1111/j.1463-1318.2009.02107.x

12 Kanda Y: Investigation of the freely available easy-to-use software 'ezr' for medical statistics. Bone Marrow Transplant 48(3): 452-458, 2013. PMID: 23208313. DOI: 10.1038/bmt. 2012.244

13 Danno K, Hata T, Tamai K, Fujie Y, Ide Y, Kim HM, Ohnishi T, Morita S, Yoshioka S, Kudo T, Nishimura J, Matsuda C, Akamatsu H, Mizushima T, Nezu R, Doki Y and Mori M: Interim analysis of a phase II trial evaluating the safety and efficacy of capecitabine plus oxaliplatin (xelox) as adjuvant therapy in japanese patients with operated stage III colon cancer. Cancer Chemother Pharmacol 80(4): 777-785, 2017. PMID: 28825216. DOI: 10.1007/s00280-017-3419-1

14 Emi Y, Kakeji Y, Oki E, Saeki H, Ando K, Kitazono M, Sakaguchi Y, Morita M, Samura H, Ogata Y, Akagi Y, Natsugoe S, Shirouzu K, Tokunaga S, Sirzen F and Maehara Y: Initial report of kscc0803: Feasibility study of capecitabine as adjuvant chemotherapy for stage III colon cancer in japanese patients. Int J Clin Oncol 18(2): 254-259, 2013. PMID: 22240888. DOI: 10.1007/s 10147-011-0371-7

15 Mochizuki I, Takiuchi H, Ikejiri K, Nakamoto Y, Kinugasa Y, Takagane A, Endo T, Shinozaki H, Takii Y, Takahashi Y, Mochizuki H, Kotake K, Kameoka S, Takahashi K, Watanabe T, Watanabe M, Boku N, Tomita N, Matsubara Y and Sugihara K: Safety of uft/lv and s-1 as adjuvant therapy for stage III colon cancer in phase III trial: Acts-cc trial. Br J Cancer 106(7): 12681273, 2012. PMID: 22415232. DOI: 10.1038/bjc.2012.86

16 Aspinall SL, Good CB, Zhao X, Cunningham FE, Heron BB, Geraci M, Passero V, Stone RA, Smith KJ, Rogers R, Shields J, Sartore M, Boyle DP, Giberti S, Szymanski J, Smith D, Ha A, Sessions J, Depcinski S, Fishco S, Molina I, Lepir T, Jean C, CruzDiaz L, Motta J, Calderon-Vargas R, Maland J, Keefe S, Tague M, Leone A, Glovack B, Kaplan B, Cosgriff S, Kaster L, TonnuMihara I, Nguyen K, Carmichael J, Clifford L, Lu K and Chatta G: Adjuvant chemotherapy for stage III colon cancer: Relative dose intensity and survival among veterans. BMC Cancer 15: 62, 2015. PMID: 25884851. DOI: 10.1186/s12885-015-1038-y

17 Morris M, Platell C, Fritschi L and Iacopetta B: Failure to complete adjuvant chemotherapy is associated with adverse survival in stage III colon cancer patients. Br J Cancer 96(5): 701-707, 2007. PMID: 17299387. DOI: 10.1038/sj.bjc.6603627

18 Schwenk W, Haase O, Neudecker J and Müller JM: Short term benefits for laparoscopic colorectal resection. Cochrane Database Syst Rev 3: Cd003145, 2005. PMID: 16034888. DOI: 10.1002/14651858.CD003145.pub2

19 Yamamoto S, Inomata M, Katayama H, Mizusawa J, Etoh T, Konishi F, Sugihara K, Watanabe M, Moriya Y and Kitano S: Short-term surgical outcomes from a randomized controlled trial to evaluate laparoscopic and open D3 dissection for stage II/III colon cancer: Japan clinical oncology group study jcog 0404 . Ann Surg 260(1): 23-30, 2014. PMID: 24509190. DOI: 10.1097/sla.0000000000000499

20 Kim RH, Kavanaugh MM and Caldito GC: Laparoscopic colectomy for cancer: Improved compliance with guidelines for chemotherapy and survival. Surgery 161(6): 1633-1641, 2017. PMID: 28027818. DOI: 10.1016/j.surg.2016.11.024

21 Messaris E, Sehgal R, Deiling S, Koltun WA, Stewart D, McKenna K and Poritz LS: Dehydration is the most common indication for readmission after diverting ileostomy creation. Dis Colon Rectum 55(2): 175-180, 2012. DOI: 10.1097/DCR. 0b013e31823d0ec5

22 Yaegashi M, Otsuka K, Kimura T, Matsuo T, Fujii H, Sato K, Takashimizu K, Hatanaka T, Yoshida T, Tono C and Sasaki A: Early renal dysfunction after temporary ileostomy construction. Surg Today 50(7): 703-710, 2019. PMID: 31865459. DOI: 10.1007/s00595-019-01938-y

23 Robertson JP, Wells CI, Vather R and Bissett IP: Effect of diversion ileostomy on the occurrence and consequences of chemotherapyinduced diarrhea. Dis Colon Rectum 59(3): 194-200, 2016. PMID: 2685593. DOI: $10.1097 /$ dcr.0000000000000531

24 Hajibandeh S, Hajibandeh S, Sarma DR, East J, Zaman S, Mankotia R, Thompson CV, Torrance AW and Peravali R: Metaanalysis of temporary loop ileostomy closure during or after adjuvant chemotherapy following rectal cancer resection: The dilemma remains. Int J Colorectal Dis 34(7): 1151-1159, 2019. PMID: 31129697. DOI: 10.1007/s00384-019-03321-2

25 Zhen L, Wang Y, Zhang Z, Wu T, Liu R, Li T, Zhao L, Deng H, Qi X and Li G: Effectiveness between early and late temporary ileostomy closure in patients with rectal cancer: A prospective study. Curr Probl Cancer 41(3): 231-240, 2017. PMID: 28434582. DOI: 10.1016/j.currproblcancer.2017.02.007

26 Brown SR, Khan B, Green HJ and Beck DE: Overall survival associated with ileostomy closure in patients with rectal cancer before and after adjuvant therapy. Ochsner J 17(4): 328-330, 2017. PMID: 29230116.

27 Sandra-Petrescu F, Herrle F, Hinke A, Rossion I, Suelberg H, Post S, Hofheinz RD and Kienle P: Cocstom trial: Study protocol for a randomised trial comparing completeness of adjuvant chemotherapy after early versus late diverting stoma closure in low anterior resection for rectal cancer. BMC Cancer 15: 923, 2015. PMID: 26589718. DOI: 10.1186/s12885-015-1838-0

Received June 8, 2020

Revised July 25, 2020

Accepted July 31, 2020 